\title{
A Physical Study to Explain Response Differences between the BID and FID Detectors for PAHs and Pesticides
}

\author{
Amanda F. Lopes, ${ }^{\circledR a}$ Florêncio S. Gouveia Jr., ${ }^{\circledR b}$ Hélio O. Nascimento, ${ }^{\circledR a}$ \\ Vitor P. A. da Silva, ${ }^{\oplus c}$ Pablo G. A. Barbosa, ${ }^{\circledR d}$ Tecia V. Carvalho ${ }^{e}$ and \\ Ronaldo F. do Nascimento ${ }^{\oplus *, a, e}$
}

${ }^{a}$ Laboratório de Análise de Traços (LAT), Departamento de Química Analítica e Físico-Química, Universidade Federal do Ceará (UFC), CP 60.440.900, 60451-970 Fortaleza-CE, Brazil

${ }^{b}$ Laboratório de Bioinorgânica, Departamento de Química Orgânica e Inorgânica, Universidade Federal do Ceará (UFC), CP 60.440.900, 60451-970 Fortaleza-CE, Brazil

'Núcleo de Inovação Tecnológica do Ceará, 60451-970 Fortaleza-CE, Brazil

'Instituto Federal de Educação, Ciência e Tecnologia, Campus Sobral, 62042-030 Sobral-CE, Brazil

eInstituto Federal de Educação, Ciência e Tecnologia do Ceará, Campus Fortaleza, Benfica, 60040-531 Fortaleza-CE, Brazil

\begin{abstract}
The dielectric barrier discharge ionization detector (BID) is one of the most modern detectors commercially available for gas chromatography (GC). Its technology based on the sample ionization through the energy released from the helium plasma generation process gives it the ability to act as a universal detector and a greater response to various types of compounds compared to the well-established flame ionization detector (FID). In this study, polycyclic aromatic hydrocarbons (PAHs), organophosphates (OPPs) and organochlorines pesticides (OCPs) were investigated. The parameters that could explain the performance of the BID and FID detectors were: structural factors, ionization energy (IE) and energy of the highest occupied molecular orbital $\left(\mathrm{E}_{\text {номо }}\right)$, which were obtained by density functional theory (DFT). The relative (BID/FID) responses to PAHs and pesticides were about 1.8 and 3.0 times greater than FID, respectively. Less structural dependence of the BID signal compared to the FID signal was observed. Among the parameters calculated by DFT, the IE was the one that most seemed to have influenced the response of the two detectors studied. The theoretical data proved to be quite consistent to explain the trends observed experimentally, especially to the BID.
\end{abstract}

Keywords: gas chromatography, dielectric barrier discharge ionization detector, flame ionization detector, density functional theory, ionization energy

\section{Introduction}

The development of sensitive detectors for trace-level analysis is of great importance in gas chromatography (GC). ${ }^{1}$ Currently, there is a wide variety of detection technologies adapted to GC, which can be specific for the determination of a certain class of chemicals (volatile and semi-volatile), such as the electron capture detector (ECD), nitrogen phosphorous detector (NPD) ${ }^{2-4}$ and others capable of detecting a wide variety of molecules, such as flame ionization detector (FID), thermal conductivity

*e-mail: ronaldo@ufc.br

Editor handled this article: Ivo M. Raimundo Jr. (Associate) detector (TCD) and the mass spectrometer (MS). Discharge ionization detector (DID) and discharge helium ionization detector (DHID) are examples of more modern detectors, based on the photoionization of the sample. ${ }^{2,3,5}$ The dielectric barrier discharge ionization detector (BID) is a detection system developed more recently for CG, belonging to the class of photoionization detectors.

The BID is based on dielectric barrier discharge technology (DBD) or "silent discharge", where a low temperature helium plasma is used as a source capable of ionizing a wide variety of gases and organic molecules. ${ }^{6,7}$ In the BID system, a high energy discharge is formed when a high voltage alternating current is applied through electrodes, being one or both electrodes covered by a 


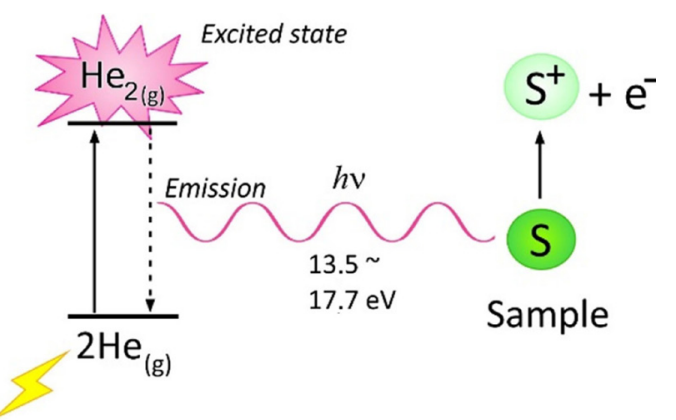

Figure 1. Illustration of the ionization process of the analyte molecules by helium plasma. DBD at the BID generates a helium plasma. Plasma energy surrounds $\mathrm{He}_{2(\mathrm{~g})}$ excited molecules $\left(\mathrm{A}^{1} \mathrm{~S}_{\mathrm{u}}{ }^{+}\right)$. The return to the fundamental state $\mathrm{He}\left(1^{1} \mathrm{~S}_{0}\right)$ generates high energy photons (between 13.5 and $\left.17.7 \mathrm{eV}\right)$ which is enough to ionize different molecules $(\mathrm{S})$ to $\mathrm{S}^{+}$.

dielectric material. ${ }^{8}$ The ionization process of the analyte molecules by helium plasma is shown in Figure 1. In the first stage, the plasma energy generates excited molecules of $\mathrm{He}_{2}\left(\mathrm{~A}_{1} \mathrm{~S}_{\mathrm{u}}^{+}\right)$in a metastable condition. In the second stage, photons are emitted during the return to the ground state He $\left(1^{1} \mathrm{~S}_{0}\right)$. The generated photons have ionization energy between 13.5 and $17.5 \mathrm{eV}$, which is sufficient to promote the ionization of a wide variety of molecules. ${ }^{69-11}$

Since the BID system became commercially available, most studies have focused on the determination of inorganic gases. ${ }^{12}$ Pascale et al..$^{13}$ measured the emission of greenhouse gases $\left(\mathrm{CO}_{2}\right.$ and $\left.\mathrm{N}_{2} \mathrm{O}\right)$ in a wastewater treatment plant; Iguchi et al. ${ }^{14,15}$ and Tokudome et al. ${ }^{16}$ monitored the catalytic conversion of $\mathrm{CO}_{2}$ to $\mathrm{CO}$ and other species $\left(\mathrm{CO}, \mathrm{H}_{2}\right.$ and $\left.\mathrm{O}_{2}\right)$; Caniani et al. ${ }^{17}$ monitored $\mathrm{CO}_{2}$ and $\mathrm{N}_{2} \mathrm{O}$ from tanks in a water resource recovery facility; Amodeo et al. ${ }^{18}$ analyzed $\mathrm{CH}_{4}$ and $\mathrm{CO}_{2}$ from a landfill; Ueta et al. ${ }^{19-22}$ used the BID coupled to a needle-type extraction device to determine formic acid, acetic acid, volatile amines and ammonia; Pascale et $a l .^{23}$ determined benzene, toluene, ethylbenzene and xylenes in water; Frink and Armstrong ${ }^{24,25}$ determined water in oil, oil products and honey; Yoo et al..$^{26}$ used large volume injection (LVI) combined with GC-BID to monitor gaseous formaldehyde. Recently, Ding et al. ${ }^{27}$ monitored the photocatalytic production of $\mathrm{H}_{2}$, using $\mathrm{Bi}_{2} \mathrm{O}_{2} \mathrm{Se}$ as a photocatalyst; Gruca-Rokosz et al. ${ }^{28,29}$ monitored $\mathrm{CH}_{4}$ and $\mathrm{CO}_{2}$ in the $\mathrm{CH}_{4}$ production pathways in freshwater sediments and on the surface of reservoirs in southeastern Poland and Szal and Gruca-Rokosz ${ }^{30}$ quantified gases from anaerobic oxidation of methane in freshwater sediments in Polish dams.

In addition, there are some comparative studies involving the BID and other detectors. Weatherly et al. ${ }^{31}$ used ionic liquid capillary gas chromatography with TCD and BID to analyze water and ethanol; Franchina et al..$^{32}$ compared the performance of the BID with the FID for the determination of 10 compounds (benzene, alcohols, fatty acids methyl esters (FAME) and two alkanes (C9 and (10)) after comprehensive two-dimensional GC. Antoniadou et al. ${ }^{33}$ conducted an interesting comparative study with GC-BID and GC-FID for the determination of alcohols, aliphatic hydrocarbons, cycloaliphatic compounds, polycyclic aromatic hydrocarbons (PAHs), and others. In addition, some disadvantages linked to the use of BID have been reported, such as a reduced dynamic range and moderately greater financial investment compared to FID, the need to use helium gas with purity above $99.999 \%$ to obtain low limits of detection, a gradual decrease in performance compared to FID for the determination of compounds with hetero atoms due to the increase in the molecular mass of the analyte and the BID does not respond linearly to the carbon mass. ${ }^{32,33}$

However, no study on the influence of physical properties (such as ionization energy (IE) and energy of the highest occupied molecular orbital $\left(\mathrm{E}_{\text {номо }}\right)$ ) on the BID's response has been reported. Thus, this work aimed to study the influence of IE and $\mathrm{E}_{\text {номо }}$ obtained by functional density theory (DFT) and chemical structures to try to explain the differences in responses between the BID and the FID for the determination of PAHs, organophosphorous pesticides (OPPs) and organochlorines (OCPs).

\section{Experimental}

\section{Reagents and standards}

Standard solutions were prepared using the following chromatographic grade solvents: acetonitrile, obtained from Applichem Panreac (Darmstadt, Germany). Dichloromethane (99.9\%) and methanol (99.8\%) from J.T. Baker, were obtained from Sigma-Aldrich, São Paulo, Brazil, respectively. The OCPs standards, atrazine, metolachlor, 1,1-dichloro-2,2-bis(4-chlorophenyl)ethane (4,4'-DDD), 1,1-dichloro-2,2-bis(4-chlorophenyl)ethene (4,4'-DDE), 1,1,1-trichloro-2,2-bis(4-chlorophenyl)ethane (4,4'-DDT), dieldrin and endrin (Sigma-Aldrich, São Paulo, Brazil).

A stock solution $\left(1000 \mu \mathrm{g} \mathrm{mL} \mathrm{m}^{-1}\right)$ of the pesticides was prepared in acetonitrile. For the analysis, a solution was prepared for each chemical class studied, containing $50 \mu \mathrm{g} \mathrm{mL}^{-1}$ of each compound.

A solution of PAHs (naphthalene; acenaphthylene; acenaphthene; anthracene; pyrene; fluoranthene; chrysene; benz $[a]$ anthracene; benzo $[k]$ fluoranthene and benzo $[a]$ pyrene) at $1000 \mu \mathrm{g} \mathrm{mL}^{-1}$ (Sigma-Aldrich, São Paulo, Brazil), was prepared in dichloromethane from the individual analytical standards. The standards of OPPs (dimethoate; 
methyl parathion; fenitrothion; triphenylphosphate; methidathion; malathion; chlorpyrifos and profenophos) were obtained from Merck, Brazil. A stock solution $\left(1000 \mu \mathrm{g} \mathrm{mL}^{-1}\right)$ in acetonitrile of the pesticides was prepared. For the analysis, a solution was prepared for each chemical class studied, where each one of the compounds was in the concentration of $50 \mu \mathrm{g} \mathrm{mL}^{-1}$.

\section{Chromatographic analysis}

The analyses were performed using the GC-BID (2010 Plus Shimadzu, Tokyo, Japan) and GC-FID (GC17 Shimadzu, Tokyo, Japan) systems. Helium 5.0 (99.999\%) was previously subjected to purification on a gas purifier obtained from VICI Valco Instruments Co. Inc, before being conducted to the chromatographic system at the BID. This gas was used for plasma generation and as carrier gas. Synthetic air 5.0 (99.999\%), hydrogen 4.5 (99.995\%) were in the FID system and hydrogen was carrier gas.

The complete separation for all the compounds studied (PAHs, OPPs and OCPs) was carried out using a Supelco Equity-5 capillary column obtained from Merck, Brazil $(30 \mathrm{~m} \times 0.25 \mathrm{~mm} \times 0.25 \mu \mathrm{m}$ film thickness $)$ with an injection volume of $1 \mu \mathrm{L}$ for both GC-BID and GC-FID systems.

The chromatographic analyzes were carried out on three different days and triplicates were obtained on each day. The medium values of the peak area were considered for the discussions. The injections $(n=3)$ were performed manually, using the same chromatographic conditions for each group of compounds in the two systems.

\section{PAHs analysis}

The conditions used were flow rate of $1.5 \mathrm{~mL} \mathrm{~min}^{-1}$, splitless injection mode, injector temperature $260^{\circ} \mathrm{C}$, split ratio: $1: 20$. Detector temperature $300^{\circ} \mathrm{C}$. Oven temperature programming: $60^{\circ} \mathrm{C}$ for $2 \mathrm{~min}$, increase $\left(25^{\circ} \mathrm{C} \mathrm{min}{ }^{-1}\right)$ to $200{ }^{\circ} \mathrm{C}$ (for $2 \mathrm{~min}$ ), increase $\left(12{ }^{\circ} \mathrm{C} \mathrm{min}^{-1}\right)$ to $300{ }^{\circ} \mathrm{C}$ and maintained for $10 \mathrm{~min}$.

\section{OPPs analysis}

The conditions used were flow rate of $1.6 \mathrm{~mL} \mathrm{~min}{ }^{-1}$, splitless injection mode, injector temperature $260{ }^{\circ} \mathrm{C}$, split ratio: $1: 20$. Detector temperature $300^{\circ} \mathrm{C}$. Oven temperature programming: $80{ }^{\circ} \mathrm{C}$ (for $1 \mathrm{~min}$ ), increase $\left(20^{\circ} \mathrm{C} \mathrm{min}-1\right)$ to $210{ }^{\circ} \mathrm{C}$ (for $1 \mathrm{~min}$ ), increase $\left(15^{\circ} \mathrm{C} \mathrm{min}^{-1}\right)$ to $300{ }^{\circ} \mathrm{C}$ (for $1 \mathrm{~min}$ ).

\section{OCPs analysis}

The conditions used were flow rate of $1.37 \mathrm{~mL} \mathrm{~min}^{-1}$, splitless injection mode, injector temperature $260{ }^{\circ} \mathrm{C}$, split ratio: 1:20. Detector temperature $300^{\circ} \mathrm{C}$. Oven temperature programming: $80^{\circ} \mathrm{C}$ (for $1 \mathrm{~min}$ ), increase $\left(20^{\circ} \mathrm{C} \mathrm{min}^{-1}\right)$ to $180^{\circ} \mathrm{C}$, increase $\left(8^{\circ} \mathrm{C} \mathrm{min}^{-1}\right)$ to $210^{\circ} \mathrm{C}$ (for $1 \mathrm{~min}$ ), increase $\left(15^{\circ} \mathrm{C} \mathrm{min}^{-1}\right)$ to $300^{\circ} \mathrm{C}$ (for $1 \mathrm{~min}$ ).

\section{DFT study}

The density functional theory (DFT) was applied as an auxiliary tool to evaluate the experimentally observed behavior of each molecule analyzed by GC-BID and GC-FID. For this, the theoretical values of ionization energy (IE) and energy of the highest occupied molecular orbital $\left(\mathrm{E}_{\text {номо }}\right)$ were obtained by simulation of the working conditions of GC-BID and GC-FID for all molecules of the classes of compounds studied by the DFT approach. Geometry optimizations were done at the DFT level for all species studied. All calculations were performed using the Gaussian 9 rev. A02 (Gaussian Inc., Wallingford, CT), ${ }^{34}$ and the functional B3LYP. ${ }^{35-37}$ Base 6-311G (d, p) was applied to all atoms. The minimum potential energy for the optimized geometries was confirmed by the absence of imaginary frequencies in the vibrational analysis calculations.

The analysis conditions were simulated by the polarization continuum model (PCM), ${ }^{38}$ using the parameters for argon. Since the gas dielectric constant values for helium and argon are quite similar, then it is possible to make such an approximation. ${ }^{39}$ The IE values were determined by the equation $1 .{ }^{40}$

$\mathrm{IE}=\mathrm{E}\left(\mathrm{M}^{+}\right)-\mathrm{E}(\mathrm{M})$

where $\mathrm{E}\left(\mathrm{M}^{+}\right)$corresponds to the energy of the ionized species and $\mathrm{E}(\mathrm{M})$ corresponds to the energy of the neutral species.

\section{Response of BID and FID detectors}

The magnitude of the detector signal usually is based on area measurement of the peak (or peak height). The evaluation of the response for BID and FID in the determination of the selected compounds was made based on the ratio between the area obtained for each compound and the mass $(2.5 \mathrm{ng})$ that was directed to the column (injection at 1:20 split mode). The data obtained experimentally for each of the four groups of compounds studied were associated with their structural characteristics and with the IE and $\mathrm{E}_{\text {номо }}$ values obtained by DFT. 


\section{Results and Discussion}

\section{Comparison between BID and FID}

BID and FID operate based on analyte ionization and detection of species generated in the presence of cold plasma and flame, respectively. However, the BID is sensitive to concentration and the FID is sensitive to mass. ${ }^{32,33}$

The chromatograms obtained using GC-BID and GC-FID were compared in Figure 2. The detectors chosen show that the responses are clearly differentiate for the compounds evaluated (PAHs, OPPs and OCPs). As shown in Figure 2, the relative (BID/FID) response was greater for the BID for the classes of compounds studied.

The influence of compound structure on FID and BID responses

The FID response to PAHs has been shown to be more dependent on the structure of these compounds with increasing molecular mass. ${ }^{33}$ However, the BID response is less dependent on the variation of the molecular mass and structure of the PAHs (Figure 3a). The relative (BID/FID) response for the PAHs shows that the BID is more sensitive than the FID around 1.8 times. The inspection of the Figure 3 indicates the BID responses are similar for PAHs-1 (linearly grouped rings: naphthalene, anthracene, benz $[a]$ anthracene and chrysene) and PAHs-2 (condensed rings: pyrene, fluoranthene, benzo[ $k]$ fluoranthene and benzo $[a]$ pyrene), while the FID response does not correlate directly with PAH structures (Figure 3).

The FID response usually is proportional to the carbon content in an organic compound that burn in the flame (air-hydrogen), but when heteroatoms ( $\mathrm{P}, \mathrm{S}, \mathrm{N}, \mathrm{O})$ are present the FID signal decreases. Clearly, the sensitivity of FID is dependent of the presence of heteroatoms in the molecule structures. ${ }^{3,4}$ In addition, the presence of electronegative substituents, like chlorine, could also contribute to suppressing the FID response. Despite that, the average number of heteroatoms present in the OPPs and some OCPs does not present a significant difference to be considered as a determinant factor on BID response. The BID proved to be more sensitive than the FID considering all the pesticides studied. The relative (BID/FID) response was around 3.0 for OPPs and OCPs. The BID seems to be less affected than the FID by the presence of heteroatoms and chlorine substituents, as can be seen for dimethoate, methyl parathion, fenitrothion, 4,4'-DDE, 4,4'-DDD and 4,4'-DDT (Figure 4).

Figure 3 shows that the BID performed well for all the OPPs studied. In this connectivity, the presence of the methyl substituent in the ortho position to the nitro group in fenitrothione may have contributed to an increase on FID response when compared to methyl parathion. This may be related to the electron donor effect of the methyl substituent and the greater possibility of this molecule breaking down when subjected to the ionization process using the FID system (Figure 3). ${ }^{3,41,42}$ Furthermore, the presence of nitrogen as a heteroatom in chlorpyrifos (see Figure 4) does not appear to have negatively compromised the BID response.

BID and FID response profiles for the OCPs are similar, except for 4,4'-DDD, but clearly the BID response showed an improved performance for the determination of this compound compared to the other OCPs. This may be related to the decrease in the electronic availability from 4,4'-DDE to 4,4'-DDT, due to the increase in the electronwithdrawing inductive effect (increase in the number of chlorine substituents) $)^{43}$ and the decrease in unsaturation. The results showed that the main influence on this trend is that the BID response is less affected by the structural
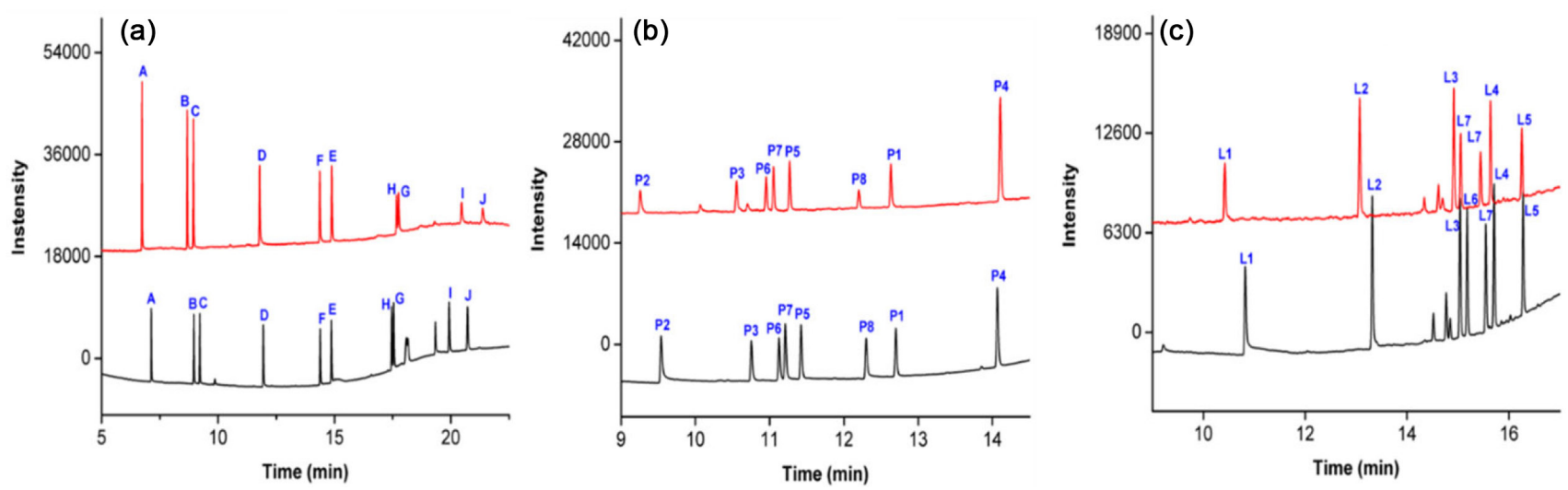

Figure 2. Chromatograms of PAHs (a); OPPs (b) and OCPs (c), studied by GC-BID (一) and GC-FID (一). Naphthalene (A); acenaphthylene (B); acenaphthene $(\mathrm{C})$; anthracene $(\mathrm{D})$; pyrene $(\mathrm{E})$; fluoranthene $(\mathrm{F})$; chrysene $(\mathrm{G})$; benz $[a]$ anthracene $(\mathrm{H})$; benzo $[k]$ fluoranthene $(\mathrm{I})$; benzo $[a]$ pyrene $(\mathrm{J})$; dimethoate (P1); methyl parathion (P2); fenitrothion (P3); triphenylphosphate (P4); methidathion (P5); malathion (P6); chlorpyrifos (P7); profenophos (P8); atrazine (L1); metolachlor (L2); 4,4'-DDE (L3); 4,4'-DDD (L4); 4,4'-DDT (L5); endrin (L6) and dieldrin (L7). 

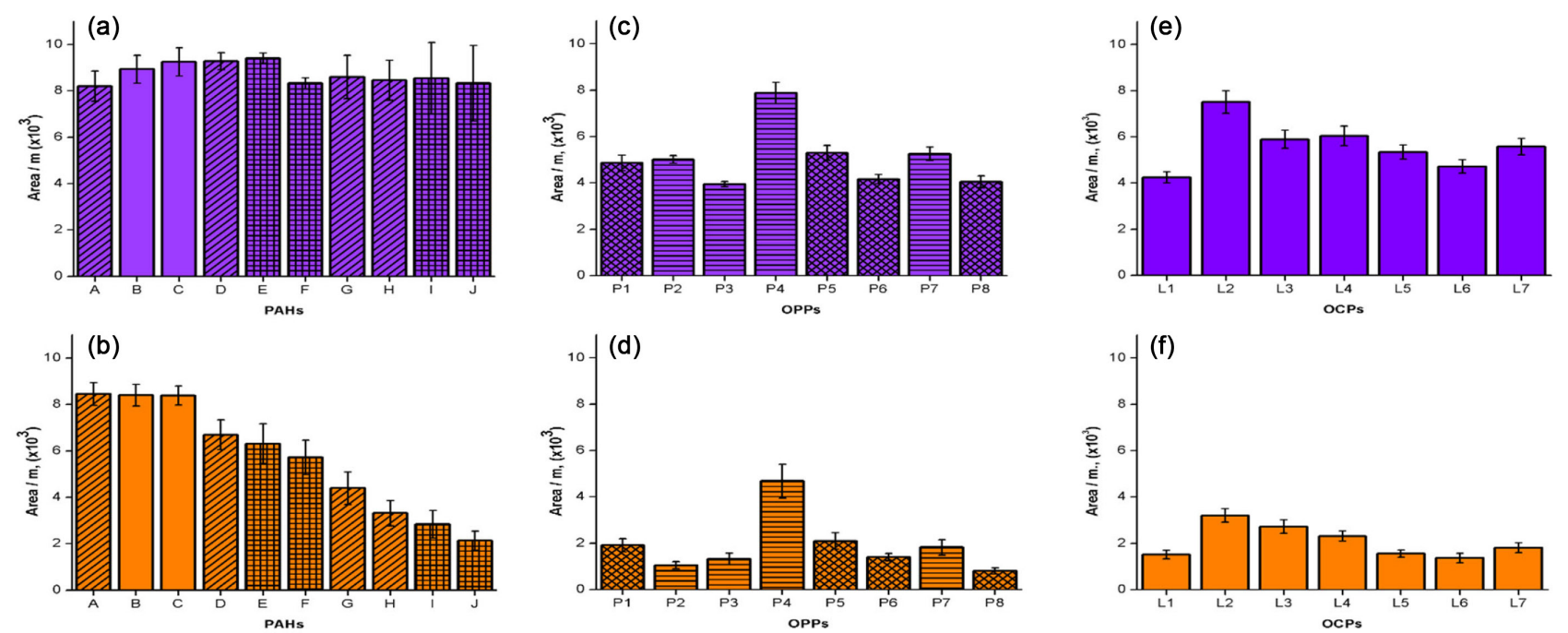

Figure 3. Responses for the classes of compounds studied by BID ( $\square$ ) and FID ( $\square$ ). The vertical bar is the ratio between the area obtained for each compound and the mass that was directed to the column (2.5 ng). (a) and (b) PAHs ( $\bar{x}=8728.30$ and $\bar{x}=5661.63)$; (c) and (d) OPPs ( $\bar{x}=5055.46$ and

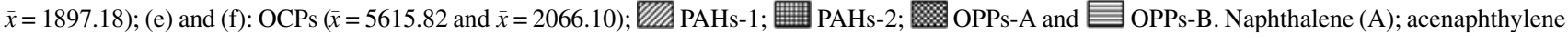
(B); acenaphthene (C); anthracene (D); pyrene (E); fluoranthene (F); chrysene (G); benz $[a]$ anthracene $(\mathrm{H})$; benzo $[k]$ fluoranthene $(\mathrm{I})$; benzo $[a]$ pyrene $(\mathrm{J})$; dimethoate (P1); methyl parathion (P2); fenitrothion (P3); triphenylphosphate (P4); methidathion (P5); malathion (P6); chlorpyrifos (P7); profenophos (P8); atrazine (L1); metolachlor (L2); 4,4'-DDE (L3); 4,4'-DDD (L4); 4,4'-DDT (L5); endrin (L6) and dieldrin (L7).

(a)

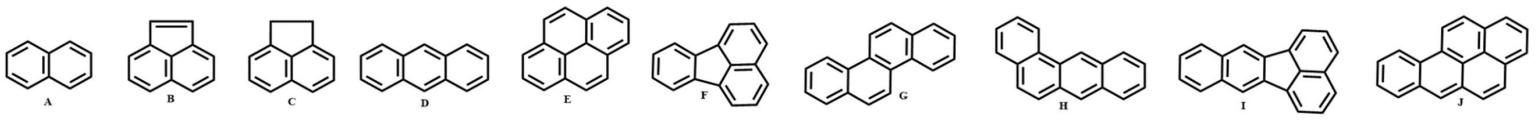

(b)

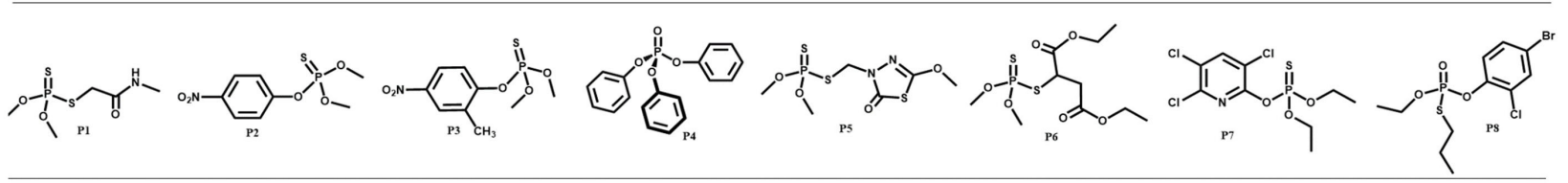

(c)
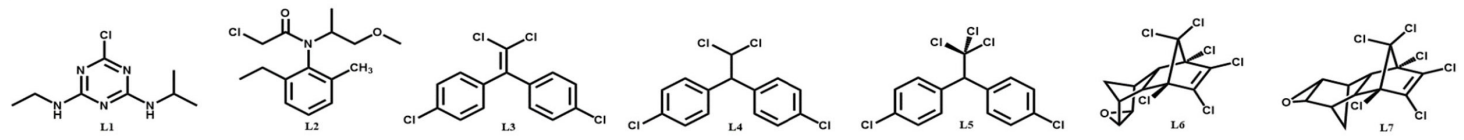

Figure 4. Structures of PAHs (a); OPPs (b) and OCPs (c), studied by GC-BID and GC-FID. Naphthalene (A); acenaphthylene (B); acenaphthene (C); anthracene $(\mathrm{D})$; pyrene $(\mathrm{E})$; fluoranthene $(\mathrm{F})$; chrysene $(\mathrm{G})$; benz $[a]$ anthracene $(\mathrm{H})$; benzo $[k]$ fluoranthene $(\mathrm{I})$; benzo $[a]$ pyrene $(\mathrm{J})$; dimethoate $(\mathrm{P} 1)$; methyl parathion (P2); fenitrothion (P3); triphenylphosphate (P4); methidathion (P5); malathion (P6); chlorpyrifos (P7); profenophos (P8); atrazine (L1); metolachlor (L2); 4,4'-DDE (L3); 4,4'-DDD (L4); 4,4'-DDT (L5); endrin (L6) and dieldrin (L7).

characteristics of the OPPs and OCPs studied. In addition, the BID response is greater than the FID for all these compounds, in particular, for profenophos and endrin.

The influence of ionization energy (IE)

For BID and FID systems, the detection process is preceded by the ionization of the analyte. Therefore, it is expected that a more efficient ionization process could lead to greater efficiency in the detection and better response. One way to measure this efficiency could be by the evaluation of the ionization energy (IE) that each compound would have in the experimental conditions of GC-BID and GC-FID. The IE values of each compound were obtained by simulating the operational conditions of the two detectors, using the computational calculation based on DFT.
First, the IE variation between BID and FID was evaluated (for each compound). Theoretical data indicated that the IE values by BID tend to be lower than by FID (Table 1). IE variations were greater than 5\% in most cases. Probably the difference in IE may be associated with the effective response of the BID for all compounds studied.

The simulated IE values for all compounds studied by BID ranged from 6.27 to $8.87 \mathrm{eV}$. These data are lower than the energy used to ionize samples at the BID (13.5 and $17.5 \mathrm{eV})$. Therefore, the results confirm that this detector has enough energy to ionize a wide variety of molecules. As result, this provides a gain in BID performance during a gas chromatography analysis. These data justify the fact that the BID was able to ionize all the studied molecules and its efficiency as a detector with the potential to analyze a wide range of organic compounds. 
Table 1. Theoretical values of ionization energy (IE) obtained under the conditions of BID and FID, and variation between BID and FID ( $\Delta$ IE) for all compounds studied

\begin{tabular}{|c|c|c|c|c|c|}
\hline \multirow{2}{*}{ Compound } & \multirow{2}{*}{ Abbreviation } & \multirow{2}{*}{ Compound class } & \multicolumn{2}{|c|}{$\mathrm{IE} / \mathrm{eV}$} & \multirow{2}{*}{$\Delta \mathrm{IE} / \%$} \\
\hline & & & BID & FID & \\
\hline Naphthalene & $\mathrm{A}$ & PAHs & 7.25 & 7.82 & 7.87 \\
\hline Acenaphthylene & B & PAHs & 7.13 & 7.67 & 7.65 \\
\hline Acenaphthene & $\mathrm{C}$ & PAHs & 6.84 & 7.38 & 7.92 \\
\hline Anthracene & $\mathrm{D}$ & PAHs & 6.53 & 7.04 & 7.80 \\
\hline Pyrene & E & PAHs & 6.59 & 7.09 & 7.54 \\
\hline Fluoranthene & F & PAHs & 7.04 & 7.53 & 7.00 \\
\hline Chrysene & $\mathrm{G}$ & PAHs & 6.71 & 7.18 & 6.97 \\
\hline Benz $[a]$ anthracene & $\mathrm{H}$ & PAHs & 6.52 & 6.99 & 7.18 \\
\hline Benzo $[k]$ fluoranthene & I & PAHs & 6.87 & 6.99 & 1.81 \\
\hline Benzo $[a]$ pyrene & $\mathrm{J}$ & PAHs & 6.27 & 6.72 & 7.28 \\
\hline Dimethoate & $\mathrm{P} 1$ & OPPs & 7.52 & 7.95 & 5.64 \\
\hline Methyl parathion & $\mathrm{P} 2$ & OPPs & 8.11 & 8.61 & 6.25 \\
\hline Fenitrothion & P3 & OPPs & 7.97 & 8.45 & 6.01 \\
\hline Triphenylphosphate & P4 & OPPs & 7.61 & 7.98 & 4.89 \\
\hline Methidathion & P5 & OPPs & 7.48 & 7.93 & 6.15 \\
\hline Malathion & P6 & OPPs & 7.54 & 7.95 & 5.44 \\
\hline Chlorpyrifos & P7 & OPPs & 7.82 & 8.27 & 5.76 \\
\hline Profenophos & P8 & OPPs & 7.56 & 8.02 & 6.06 \\
\hline Atrazine & L1 & OCPs & 7.80 & 8.23 & 5.52 \\
\hline Metolachlor & L2 & OCPs & 7.52 & 7.92 & 5.30 \\
\hline 4,4'-DDE & L3 & OCPs & 7.32 & 7.80 & 6.60 \\
\hline 4,4'-DDD & L4 & OCPs & 7.69 & 8.19 & 6.45 \\
\hline 4,4'-DDT & L5 & OCPs & 7.74 & 8.23 & 6.25 \\
\hline Endrin & L6 & OCPs & 8.12 & 8.64 & 6.38 \\
\hline$\underline{\text { Dieldrin }}$ & L7 & OCPs & 8.29 & 8.81 & 6.33 \\
\hline
\end{tabular}

BID: dielectric barrier discharge ionization detector; FID: flame ionization detector; PAHs: polycyclic aromatic hydrocarbon; OPPs: organophosphate pesticides; OCPs: organochlorine pesticides; 4,4'-DDD: 1,1-dichloro-2,2-bis(4-chlorophenyl)ethane; 4,4'-DDE: 1,1-dichloro-2,2-bis(4-chlorophenyl) ethene; 4,4'-DDT: 1,1,1-trichloro-2,2-bis(4-chlorophenyl)ethane.

In general, the BID and FID responses showed a dependence with the IE calculated by the DFT. The inspection of the graphs (Figure 5) shows that inverse proportionality profiles were obtained for OPPs and PAHs, with a trend towards OPPs-B and some HPAs.

The contribution of IE reduction in the response increase was expected, since a lower energy demand favors the ionization process. In addition, the increased performance of the BID response for acenaphthene, compared to acenaphthylene, could be associated with a greater susceptibility of acenaphthene to undergo ionization in the BID system. As noted earlier, the BID response showed little dependence with IE for OPPs-B, in contrast a better fit of the data for methyl parathion and fenitrothion was observed for the FID.

Furthermore, the IE suggests that chlorpyrifos is more susceptible to ionization than parathion and fenitrothion for both detectors. However, it was not possible to observe a strong dependence between IE on the BID and FID responses for the OCPs studied here.

BID and FID act in the generation of charged species, which occurs through endothermic processes, as verified through the ionization energy values determined by computer simulation (Table 1). The FID is a specific detector, with high sensitivity, based on the combustion of the organic sample, producing carbon oxides and water (both undetectable, since are neutral molecules) as well as charged species, such is the cation $\mathrm{HCO}^{+}$, which can be detected. ${ }^{2,44}$ However, the high temperature and chemical composition of the flame does not favor the existence of ions, making them short-lived species in those conditions..$^{45}$ This may reflect the low detectable signal produced by some molecules using FID. On the other hand, the photoionization process of the BID may have fewer parallel reactions, since its performance does not depend of combustion reactions. Clearly, this seems to have a great contribution on BID response for good quantitative analysis of the compounds studied.

The influence of $\mathrm{HOMO}$ energy ( $\left.\mathrm{E}_{\text {номо }}\right)$

The HOMO (highest occupied molecular orbital) and LUMO (lowest unoccupied molecular orbital) are characterized as frontier orbitals of a given molecule. ${ }^{46} \mathrm{In}$

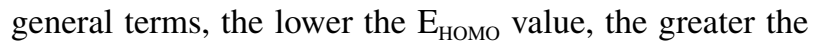
energy difference between HOMO and LUMO and the more stable the boundary orbitals will be. The stability of these orbitals is directly linked to the ease of a molecule 
(a)
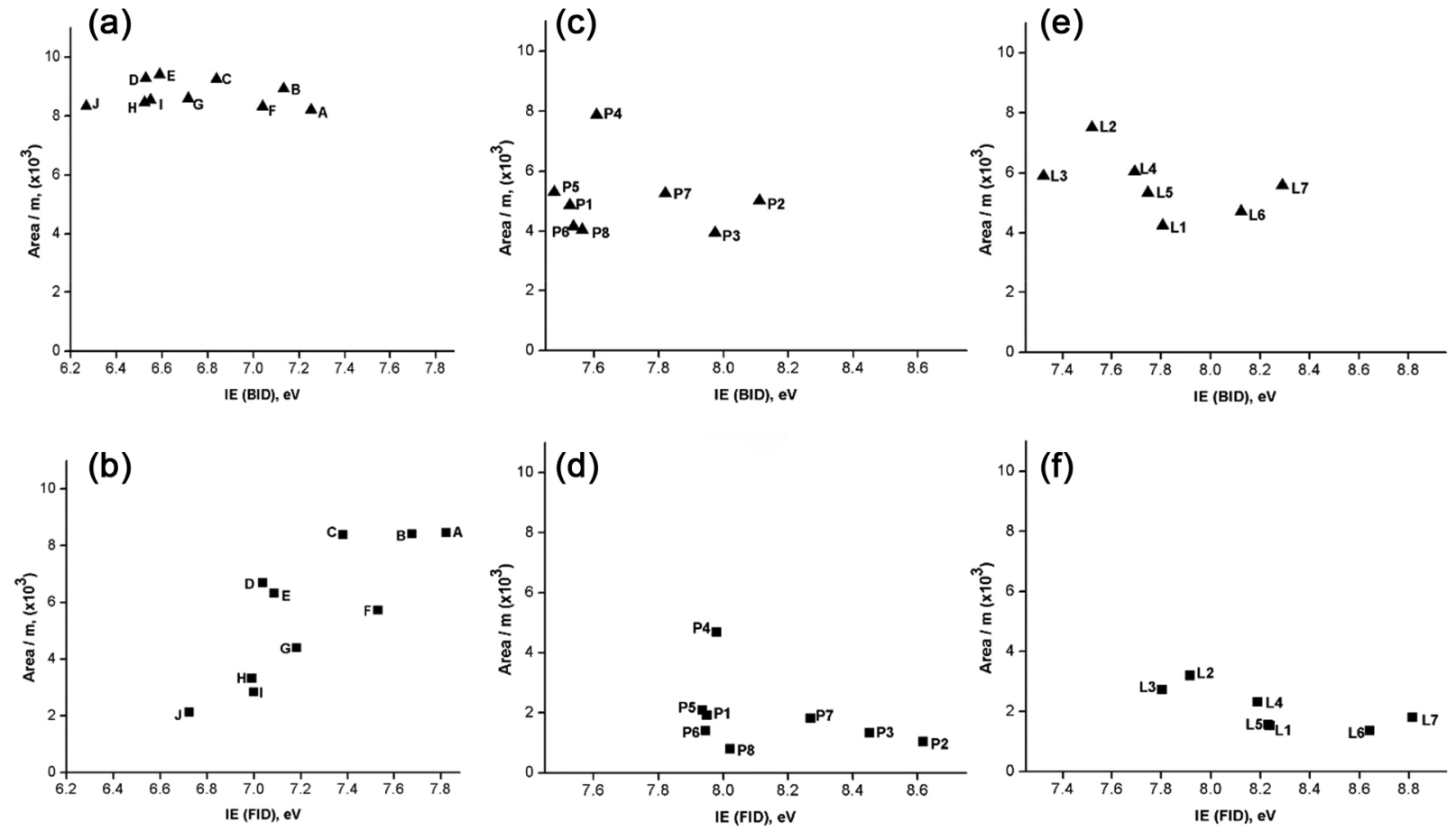

Figure 5. Response versus IE calculated under the conditions of the BID ( $\mathbf{\Delta}$ ) and FID ( $\boldsymbol{\square}$ ) for the studied classes of compounds. PAHs (a and b); OPPs (c and d) and OCPs (e and f). Naphthalene (A); acenaphthylene (B); acenaphthene (C); anthracene (D); pyrene (E); fluoranthene (F); chrysene (G); benz $[a]$ anthracene $(\mathrm{H})$; benzo $[k]$ fluoranthene $(\mathrm{I})$; benzo $[a]$ pyrene $(\mathrm{J})$; dimethoate $(\mathrm{P} 1)$; methyl parathion $(\mathrm{P} 2)$; fenitrothion $(\mathrm{P} 3)$; triphenylphosphate $(\mathrm{P} 4)$; methidathion (P5); malathion (P6); chlorpyrifos (P7); profenophos (P8); atrazine (L1); metolachlor (L2); 4,4'-DDE (L3); 4,4'-DDD (L4); 4,4'-DDT (L5); endrin (L6) and dieldrin (L7).

in losing electrons. ${ }^{47,48}$ Considering that, during oxidative processes, the lost electrons leave the $\mathrm{HOMO}, \mathrm{E}_{\mathrm{HOмо}}$ has often been associated with ionization energy. ${ }^{47-49}$

In this context, similarly to the IE, calculations based on DFT were applied to obtain the $\mathrm{E}_{\text {номо }}$ of all the compounds studied in this work and these data were used in an attempt to make correlations with the responses obtained experimentally. As expected, there was a good agreement between the calculated IE and $\mathrm{E}_{\text {номо values }}$ in all situations, except for OPPs-B, which showed more sudden variations in the energy of the frontier orbitals than IE, resulting in a greater dispersion of data (Figure 6). In general, the simulation model based on the DFT theory was able to predict the relationship between IE and $\mathrm{E}_{\mathrm{HOMO}}$ and experimental trends (with good acceptance). On the other hand, three sets of OCPs: (endrin and dieldrin), (4,4'-DDE, metolachlor and 4,4'-DDT) and (atrazine and 4,4'-DDD) are few affected by $\mathrm{E}_{\text {номо }}$ and presented a pattern similar to IE by BID and FID.

Similarly to IE, a relationship between the BID response and $\mathrm{E}_{\text {Hомо }}$ was observed for HPAs and some OPPs. Furthermore, the greater stabilization of the HOMO may be associated with a lower response observed for fenitrothion compared to methyl parathion.

As shown in Figure 7, the FID response is more dependent of the contribution of IE as can be identified in the OPPs analysis. In addition, although the calculations indicate a low variation of the $\mathrm{E}_{\text {номо }}$ values between three groups of OCPs studied, it is possible to use this parameter to explain the responses of these compounds in the two detection systems, except for endrin and dieldrin.

\section{Conclusions}

A study of the influence of parameters that may be associated with the intensity of BID and FID responses to PAHs, OPPs and OCPs has been investigated.

The BID response presented better performance than the FID for the analysis of all studied compounds, and a lower dependence on the structural variation of the compounds, mainly for PAHs. The best performance on BID response could also be associated with lower IE values obtained by the BID.

In contrast to FID, the BID response is less dependent on the molecular mass of the compounds, and less affected by the presence of heteroatoms and electrophilic substituents.

It has been shown that $\mathrm{E}_{\text {Номо }}$ is a good alternative to explain a better BID performance in several situations. However, IE seems to be the parameter that most contributed to the response of the two detectors, since the IE values showed a better fit to the experimental data obtained for most compounds studied. 
(a)

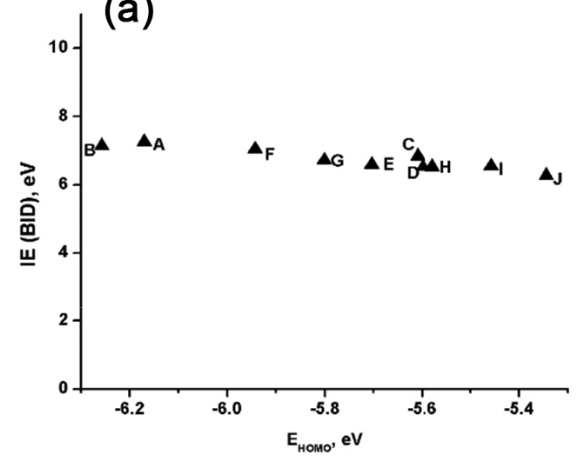

(b)

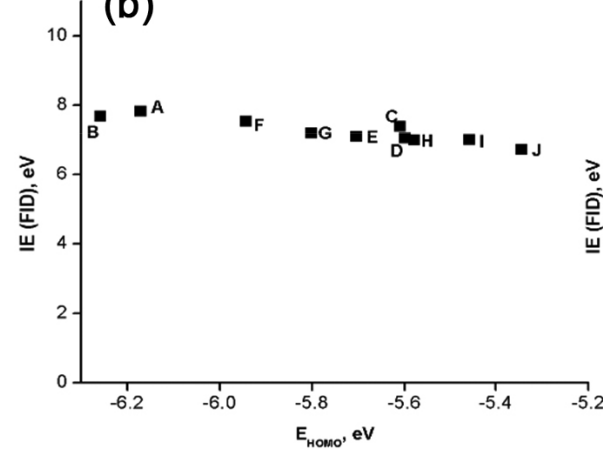

(c)

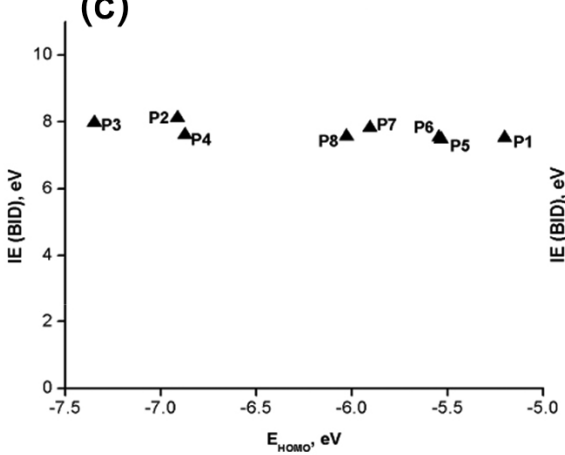

(d)

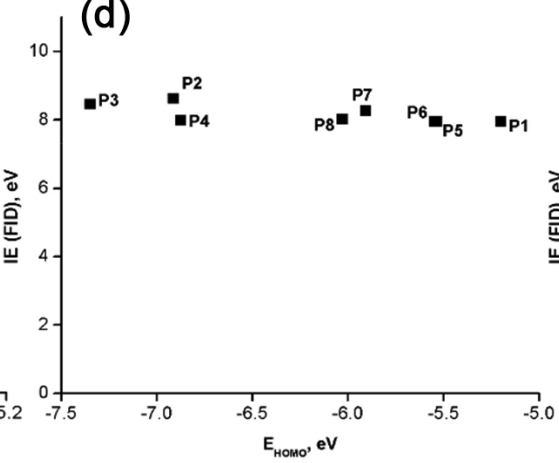

(e)

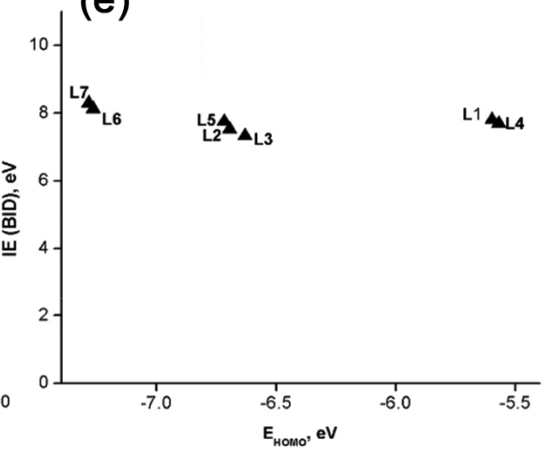

(f)

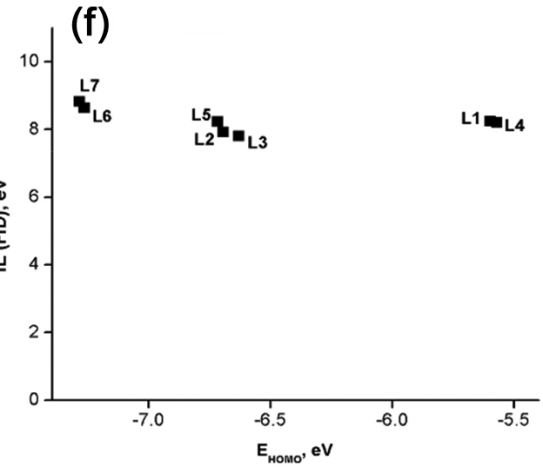

Figure 6. IE versus $\mathrm{E}_{\text {номо }}$ calculated under BID conditions ( $\boldsymbol{\Delta}$ ) and FID (ם) for the studied classes of compounds. PAHs (a and b); OPPs (c and d) and OCPs (e and f). Naphthalene (A); acenaphthylene (B); acenaphthene (C); anthracene (D); pyrene (E); fluoranthene (F); chrysene (G); benz $[a]$ anthracene (H); benzo[k]fluoranthene (I); benzo[a]pyrene (J); dimethoate (P1); methyl parathion (P2); fenitrothion (P3); triphenylphosphate (P4); methidathion (P5); malathion (P6); chlorpyrifos (P7); profenophos (P8); atrazine (L1); metolachlor (L2); 4,4'-DDE (L3); 4,4'-DDD (L4); 4,4'-DDT (L5); endrin (L6) and dieldrin (L7).
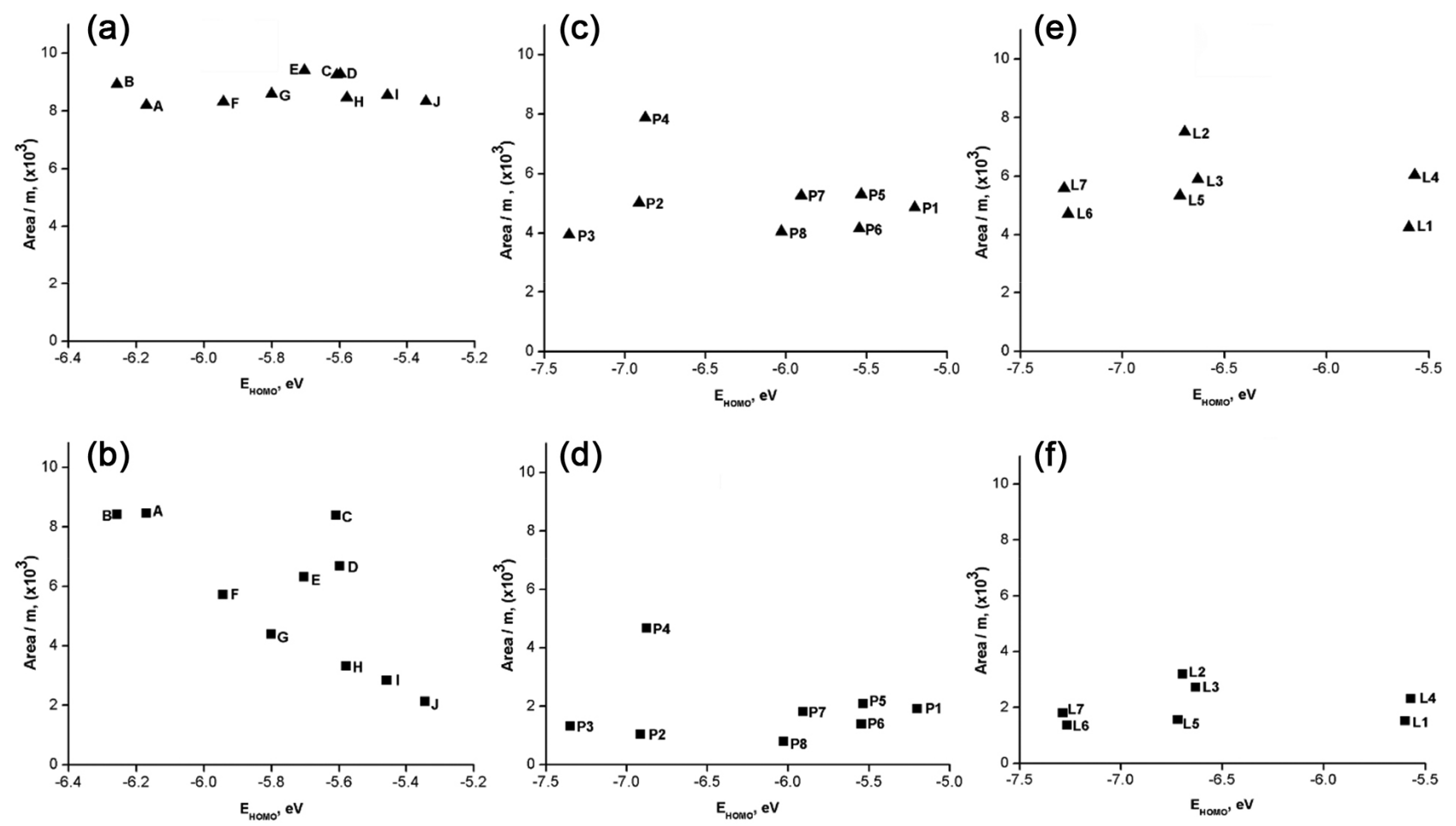

Figure 7. Response versus $\mathrm{E}_{\text {номо }}$ calculated under BID conditions ( $\left.\mathbf{\Delta}\right)$ and FID ( $\left.\mathbf{\square}\right)$ for the studied classes of compounds. PAHs (a and b); OPPs (c and d) and OCPs (e and f). Naphthalene (A); acenaphthylene (B); acenaphthene (C); anthracene (D); pyrene (E); fluoranthene (F); chrysene (G); benz $[a]$ anthracene $(\mathrm{H})$; benzo $[k]$ fluoranthene $(\mathrm{I})$; benzo $[a]$ pyrene $(\mathrm{J})$; dimethoate $(\mathrm{P} 1)$; methyl parathion $(\mathrm{P} 2)$; fenitrothion $(\mathrm{P} 3)$; triphenylphosphate $(\mathrm{P} 4)$; methidathion (P5); malathion (P6); chlorpyrifos (P7); profenophos (P8); atrazine (L1); metolachlor (L2); 4,4'-DDE (L3); 4,4'-DDD (L4); 4,4'-DDT (L5); endrin (L6) and dieldrin (L7). 


\section{Acknowledgments}

The authors thank to Trace Analysis Laboratory (LAT), Federal University of Cearal (UFC), CNPq (process: No. 432095/2018-7; No. 305074/2018-0); FUNCAP and CAPES for a PhD scholarship granted. Also to CENAPAD-UFC for the access to the computer facilities. The authors are also grateful to Marcos Carvalho for his help with the figures.

\section{Author Contributions}

Amanda F. Lopes was responsible for conceptualization, data curation, investigation, project administration, visualization, writing original draft, and writing-review and editing; Florêncio S. Gouveia Júnior for conceptualization, data curation, investigation and writing original draft; Hélio O. Nascimento for conceptualization, data curation and investigation; Vitor P. A. da Silva for conceptualization, data curation, and investigation; Pablo G. A. Barbosa for conceptualization, data curation, and investigation; Tecia for conceptualization and investigation; Ronaldo F. do Nascimento for conceptualization, investigation, project administration, resources, and writing-review and editing.

\section{References}

1. Pedroso, M. P.; de Godoy, L. A. F.; Fidélis, C. H. V.; Ferreira, E. C.; Poppi, R. J.; Augusto, F.; Quim. Nova 2009, 32, 421.

2. Poole, C. F.; J. Chromatogr. A 2015, 1421, 137.

3. McNair, H. M.; Miller, J. M.; Basic Gas Chromatography, $2^{\text {nd }}$ ed.; Wiley: New Jersey, USA, 2009.

4. do Nascimento, R.; Clecius, A.; Barbosa, P.; Silva, V.; Cromatografia Gasosa Aspectos Teóricos e Práticos; Imprensa Universitária UFC: Fortaleza, Brazil, 2019.

5. Colón, L. A.; Baird, L. J. In Modern Practice of Gas Chromatography, $4^{\text {th }}$ ed.; Grob, R. L.; Barry, E. F., eds.; Wiley: New Jersey, USA, 2004, p. 275.

6. Development of New Ionization Detector for Gas Chromatography by Applying Dielectric Barrier Discharge; https://www.semanticscholar.org/paper/Development-ofNew-Ionization-Detector-for-Gas-by-Shinada-Horiike/6c b4b9a090ff06822eed40057b0ad3093dc73caf, accessed in March 2022.

7. Sasaki, T. A.; Wilkins, C. L.; J. Chromatogr. A 1999, 842, 341.

8. Guo, C.; Tang, F.; Chen, J.; Wang, X.; Zhang, S.; Zhang, X.; Anal. Bioanal. Chem. 2015, 407, 2345.

9. Schmieder, D.; Salamon, T. I.; Opt. Commun. 1985, 55, 49.

10. Shinada, K.; Horiike, S.; US pat. 20150253286, 2015.

11. Leißing, M.; Winter, M.; Wiemers-Meyer, S.; Nowak, S.; J. Chromatotogr. A 2020, 1622, 461122.

12. Lopes, A. F.; Fernandes, T. S. M.; do Nascimento, R. F.; Crit. Rev. Anal. Chem. in press, DOI: 10.1080/10408347.2021.1969885.
13. Pascale, R.; Caivano, M.; Buchicchio, A.; Mancini, I. M.; Bianco, G.; Caniani, D.; J. Chromatogr. A 2017, 1480, 62.

14. Iguchi, S.; Teramura, K.; Hosokawa, S.; Tanaka, T.; Phys. Chem. Chem. Phys. 2015, 17, 17995.

15. Iguchi, S.; Teramura, K.; Hosokawa, S.; Tanaka, T.; Catal.: Sci. Technol. 2016, 6, 4978.

16. Tokudome, Y.; Fukui, M.; Iguchi, S.; Hasegawa, Y.; Teramura, K.; Tanaka, T.; Takemoto, M.; Katsura, R.; Takahashi, M.; J. Mater. Chem. A 2018, 6, 9684.

17. Caniani, D.; Caivano, M.; Pascale, R.; Bianco, G.; Mancini, I. M.; Masi, S.; Mazzone, G.; Firouzian, M.; Rosso, D.; Sci. Total Environ. 2019, 648, 1130.

18. Amodeo, C.; Sofo, A.; Tito, M. T.; Scopa, A.; Masi, S.; Pascale, R.; Mancini, I. M.; Caniani, D.; J. Environ. Sci. Health, Part A 2018, 53, 825 .

19. Ueta, I.; Nakamura, Y.; Fujimura, K.; Kawakubo, S.; Saito, Y.; Chromatographia 2017, 80, 151.

20. Ueta, I.; Nakamura, Y.; Kawakubo, S.; Saito, Y.; Anal. Sci. 2018, 34, 201.

21. Ueta, I.; Nakamura, Y.; Fujikawa, H.; Fujimura, K.; Saito, Y.; Chromatographia 2019, 82, 317.

22. Ueta, I.; Fujikawa, H.; Fujimura, K.; Saito, Y.; Anal. Sci. 2019, 35, 759.

23. Pascale, R.; Bianco, G.; Calace, S.; Masi, S.; Mancini, I. M.; Mazzone, G.; Caniani, D.; J. Chromatogr. A 2018, 1548, 10.

24. Frink, L. A.; Armstrong, D. W.; Anal. Chem. 2016, 88, 8194.

25. Frink, L. A.; Armstrong, D. W.; Food Chem. 2016, 205, 23.

26. Yoo, M.-J.; Jo, S.-H.; Kim, K.-H.; Microchem. J. 2019, 147, 806.

27. Ding, D.; Jiang, Z.; Ji, D.; Nosang Vincent, M.; Zan, L.; Chem. Eng. J. 2020, 400, 125931.

28. Gruca-Rokosz, R.; Szal, D.; Bartoszek, L.; Pękala, A.; CATENA 2020, 195, 104803.

29. Gruca-Rokosz, R.; Atmosphere 2020, 11, 286.

30. Szal, D.; Gruca-Rokosz, R.; Water 2020, 12, 398.

31. Weatherly, C. A.; Woods, R. M.; Armstrong, D. W.; J. Agric. Food Chem. 2014, 62, 1832.

32. Franchina, F. A.; Maimone, M.; Sciarrone, D.; Purcaro, G.; Tranchida, P. Q.; Mondello, L.; J. Chromatogr. A 2015, 1402, 102.

33. Antoniadou, M.; Zachariadis, G. A.; Rosenberg, E.; Anal. Lett. 2019, 52, 2822.

34. Frisch, M. J.; Trucks, G. W.; Schlegel, H. B.; Scuseria, G. E.; Robb, M. A.; Cheeseman, J. R.; Scalmani, G.; Barone, V.; Petersson, G. A.; Nakatsuji, H.; Li, X.; Caricato, M.; Marenich, A. V.; Bloino, J.; Janesko, B. G.; Gomperts, R.; Mennucci, B.; Hratchian, H. P.; Ortiz, J. V.; Izmaylov, A. F.; Sonnenberg, J. L.; Williams; Ding, F.; Lipparini, F.; Egidi, F.; Goings, J.; Peng, B.; Petrone, A.; Henderson, T.; Ranasinghe, D.; Zakrzewski, V. G.; Gao, J.; Rega, N.; Zheng, G.; Liang, W.; Hada, M.; Ehara, M.; Toyota, K.; Fukuda, R.; Hasegawa, J.; Ishida, M.; Nakajima, 
T.; Honda, Y.; Kitao, O.; Nakai, H.; Vreven, T.; Throssell, K.; Montgomery Jr., J. A.; Peralta, J. E.; Ogliaro, F.; Bearpark, M. J.; Heyd, J. J.; Brothers, E. N.; Kudin, K. N.; Staroverov, V. N.; Keith, T. A.; Kobayashi, R.; Normand, J.; Raghavachari, K.; Rendell, A. P.; Burant, J. C.; Iyengar, S. S.; Tomasi, J.; Cossi, M.; Millam, J. M.; Klene, M.; Adamo, C.; Cammi, R.; Ochterski, J. W.; Martin, R. L.; Morokuma, K.; Farkas, O.; Foresman, J. B.; Fox, D. J.; Gaussian 16 Rev. B.01, Wallingford, CT, 2016.

35. Stephens, P. J.; Devlin, F. J.; Chabalowski, C. F.; Frisch, M. J.; J. Phys. Chem. 1994, 98, 11623.

36. Becke, A. D.; J. Chem. Phys. 1993, 98, 5648.

37. Lee, C.; Yang, W.; Parr, R. G.; Phys. Rev. B 1988, 37, 785.

38. Tomasi, J.; Mennucci, B.; Cammi, R.; Chem. Rev. 2005, 105, 2999.

39. Haynes, W. M.; Lide, D. R.; Bruno, T. J.; Handbook of Chemistry and Physics, $97^{\text {th }}$ ed.; CRC Press: New York, USA, 2016.

40. Zhan, C.-G.; Nichols, J. A.; Dixon, D. A.; J. Phys. Chem. A 2003, 107, 4184.
41. Rondino, F.; Catone, D.; Mattioli, G.; Bonapasta, A.; Bolognesi, P.; Casavola, A.; Coreno, M.; O’Keeffe, P.; Avaldi, L.; RSCAdv. 2014, 4, 5272.

42. Salvatella, L.; Educ. Quim. 2017, 28, 232.

43. Inami, K.; Iizuka, Y.; Furukawa, M.; Nakanishi, I.; Ohkubo, K.; Fukuhara, K.; Fukuzumi, S.; Mochizuki, M.; Bioorg. Med. Chem. 2012, 20, 4049.

44. Becker, C.; Jochmann, M. A.; Schmidt, T. C.; TrAC, Trends Anal. Chem. 2019, 110, 143.

45. Kállai, M.; Balla, J.; Chromatographia 2002, 56, 357.

46. Pereira, D.; La Porta, F.; Santiago, R.; Garcia, D.; Ramalho, T.; Rev. Virtual Quim. 2016, 8, 425.

47. Dance, I.; Inorg. Chem. 2006, 45, 5084.

48. Batista, V. H. S. C.; Granato, A. C.; Angelotti, W. F. D.; Quim. Nova 2016, 39, 298.

49. Conradie, J.; J. Phys.: Conf. Ser. 2015, 633, 012045.

Submitted: May 23, 2021

Published online: March 4, 2022 